\title{
In Vitro Degradation Behavior of Microspheres Based on Cross-Linked Dextran
}

\author{
Karin D. F. Vlugt-Wensink, ${ }^{*},, \|$ Xulin Jiang, ${ }^{\dagger}$ Geert Schotman, ${ }^{\ddagger}$ Govert Kruijtzer, ${ }^{\ddagger}$ \\ Arjen Vredenberg, ${ }^{\ddagger}$ Jin T. Chung,, Zao Zhang, ${ }^{\S}$ Cees Versluis, ${ }^{\perp}$ Delphine Ramos," \\ Ruud Verrijk," Wim Jiskoot, ${ }^{\dagger}, \#$ Daan J. A. Crommelin, ${ }^{\dagger, \|}$ and Wim E. Hennink ${ }^{\dagger}$ \\ Department of Pharmaceutics, Utrecht Institute for Pharmaceutical Sciences, Utrecht University, \\ P. O. Box 80082, 3508 TB Utrecht, The Netherlands, Debye Institute, Surfaces, Interfaces and Devices, \\ Utrecht University, P. O. Box 80000, 3508 TA Utrecht, The Netherlands, Centre for Formulation \\ Engineering, Chemical Engineering, School of Engineering, The University of Birmingham, \\ Edgbaston, Birmingham, B15 2TT, UK, OctoPlus Technologies, OctoPlus b.v., Zernikedreef 12, 2333 CL, \\ Leiden, The Netherlands, Department of Biomolecular Mass Spectrometry, Utrecht Institute for \\ Pharmaceutical Sciences, Utrecht University, P. O. Box 80082, 3508 TB Utrecht, The Netherlands, and \\ Department of Drug Delivery Technology, Leiden/Amsterdam Center for Drug Research, Leiden University, \\ P. O. Box 95022300 RA, Leiden, The Netherlands
}

Received April 19, 2006; Revised Manuscript Received August 17, 2006

\begin{abstract}
The aim of this study was to investigate the in vitro degradation of hydroxyl ethyl methacrylated dextran (dexHEMA) microspheres. Dextran microspheres were incubated in phosphate buffer $\mathrm{pH} 7.4$ at $37^{\circ} \mathrm{C}$, and the dry mass, mechanical strength, and chemical composition of the microspheres were monitored in time. The amount and nature of the formed degradation products were established for microspheres with different cross-link densities by FT-IR (Fourier transformed infrared spectroscopy), NMR, mass spectrometry, SEC analysis, and XPS (X-ray photoelectron microscopy). The dex-HEMA microspheres DS 12 (degree of HEMA substitution; the number of HEMA groups per 100 glucose units) incubated at $\mathrm{pH} 7.4$ and $37{ }^{\circ} \mathrm{C}$ showed a continuous mass loss, leaving after 6 months a residue of about $10 \%(\mathrm{w} / \mathrm{w})$ of water-insoluble products. NMR, mass spectrometry, and SEC showed that the water-soluble degradation products consisted of dextran, low molecular weight pHEMA $\left(M_{\mathrm{n}} \approx\right.$ $15 \mathrm{~kg} / \mathrm{mol}$ ), and small amounts of unreacted HEMA and HEMA-DMAP (intermediate reaction product of the Baylis-Hillman reaction of HEMA with DMAP (4-dimethyl aminopyridine)). Microscopy revealed that the waterinsoluble residue consisted of particles with shape and size similar to that of nondegraded microspheres. However, these particles had lost their mechanical strength as evidenced from micromanipulation experiments. FT-IR and XPS (X-ray photoelectron microscopy) revealed that these particles consisted of pHEMA, of which a small fraction was soluble in methanol $\left(M_{\mathrm{n}}\right.$ ranging between 27 and $\left.82 \mathrm{~kg} / \mathrm{mol}\right)$. The insoluble material likely consisted of lightly cross-linked pHEMA. In conclusion, in vitro degradation of dex-HEMA microspheres results in the formation of water-soluble degradation products (mainly dextran), leaving a small water-insoluble residue mainly consisting of pHEMA.
\end{abstract}

\section{Introduction}

Biodegradable polymeric microparticles have been intensively investigated as controlled release systems for pharmaceutically active proteins. ${ }^{1}$ A major advantage of these microparticles is the possibility to tune the release rate of the proteins by their degradation rate. ${ }^{1-3}$ Moreover, there is no need for surgical removal of these systems after they have released their payload. In general, the suitability of devices based on biodegradable polymers as a protein releasing matrix depends not only on the possibility to tune the release rate, but also on the degradation time, and the biocompatibility of the polymers and their degradation products. ${ }^{2,3}$ Therefore, it is important to have good

* Corresponding author. Tel.: +31 71 5271736. Fax: +31 715244043. E-mail: wensink@octoplus.nl.

$†$ Department of Pharmaceutics, Utrecht University.

Debye Institute, Utrecht University.

$\S$ The University of Birmingham.

"OctoPlus Technologies.

${ }^{\perp}$ Department of Biomolecular Mass Spectrometry, Utrecht University.

\# Leiden University. insight into the nature of the products that are formed during degradation of the drug delivery system.

Systems based on poly(D,L-lactic-co-glycolic acid) (PLGA) have been widely studied as controlled release systems, because of their biodegradability and good biocompatibility. Under physiological conditions, these systems ultimately degrade into lactic and glycolic acid, which may enter the Krebs cycle or are excreted through the normal pathways. However, there are a number of problems associated with the application of these systems for protein delivery, among which the use of organic solvents for preparation of the protein loaded particles, the $\mathrm{pH}$ drop during degradation, and subsequently incomplete release as a result of undesired protein aggregation/degradation. ${ }^{4-7}$ Similar problems were also observed for microspheres based on other hydrophobic biodegradable polymers such as poly(ortho esters) (POE) and poly(anhydrides). ${ }^{8-11}$ The hydrophobic character of these polymers requires protein-unfriendly formulation techniques such as solvent removal or hot melt encapsulation. ${ }^{12,13}$

Because of their high water content, hydrogels are generally compatible with both living tissue and proteins. ${ }^{14-17}$ Therefore, 
hydrogel-based microspheres are a good alternative for the microsphere systems based on hydrophobic polymers. Franssen and Stekenes et al. described a method to prepare hydrogelbased dextran microspheres in an all-aqueous system, thereby avoiding the use of organic solvents. ${ }^{18,19}$ With this method, microspheres were obtained by polymerization of aqueous droplets containing methacrylated dextran in a continuous poly(ethylene glycol) (PEG) phase. However, these microspheres were essentially nondegradable without the addition of a matching enzyme (Dextranase). ${ }^{20,21}$ Biodegradable microspheres, that contain an additional carbonate ester in their cross-links, which are hydrolytically sensitive under physiological conditions, were obtained by cross-linking hydroxyethyl methacrylated dextran (dex-HEMA). ${ }^{22}$ Important features of these microspheres are their high encapsulation efficiency for proteins, a low or even absent burst release, and the possibility to tailor the release profiles by the degree of substitution of dex-HEMA (DS, number of HEMA groups per 100 glucose units) and the initial water content of the microspheres. ${ }^{22-24}$ In vivo studies performed by Cadée et al. showed these microspheres to be biocompatible. ${ }^{24}$

Previous studies have shown that dex-HEMA microspheres degrade under physiological conditions through hydrolysis of the carbonate esters linking dextran and pHEMA.22,24-30 Therefore, dextran and pHEMA are the expected degradation products. It was indeed demonstrated that dextran, a watersoluble polymer, was released from dex-HEMA microspheres and macrogels when the main fraction of cross-links was hydrolyzed. ${ }^{22,24-30}$ However, the solubility and molecular weight of the expected pHEMA degradation products have not been studied so far. Recently, Weaver at al. reported that the solubility of pHEMA depends on the degree of polymerization (DP). ${ }^{31}$ Homopolymers up to a DP of 20 are water-soluble, whereas higher molecular weight pHEMA is water-swellable rather than water-soluble. Therefore, the degradation of dex-HEMA microspheres may result in the formation of water-insoluble degradation products.

The aim of this study was to investigate the in vitro degradation of hydroxylethyl methacrylated dextran (dexHEMA) microspheres. Dextran microspheres with different cross-link densities were incubated in phosphate buffer $\mathrm{pH} 7.4$ at $37{ }^{\circ} \mathrm{C}$, and the mass, mechanical strength, and chemical composition of the microspheres were monitored in time. The amount and nature of the formed soluble degradation products were established via FT-IR, NMR, XPS, mass spectrometry, and SEC analysis.

\section{Experimental Section}

2.1. Materials. Poly(ethylene glycol) (PEG) $10 \mathrm{~kg} / \mathrm{mol}$, potassium peroxodisulfate (KPS), cesium iodide (CsI), sodium iodide (NaI), and potassium bromide $(\mathrm{KBr})$ were obtained from Merck, Darmstadt, Germany. Dextran 20 and $40 \mathrm{~kg} / \mathrm{mol}, N, N, N^{\prime}, N^{\prime}$-tetramethylethylenediamine (TEMED), 4-(dimethylamino)pyridine (DMAP), and hydroxyethyl methacrylate (HEMA) were purchased from Fluka (Buchs, Switzerland). 2,2'-Azobisisobutyronitrile (AIBN) was obtained from Polysciences, Inc. (Eppelheim, Germany). Hydroxyethyl methacrylatederivatized dextrans (dex-HEMA) with a DS of 8, 12, 16, and 20 were synthesized and characterized according to Van Dijk-Wolthuis et al. ${ }^{32}$ The degree of HEMA substitution (DS, the number of HEMA groups per 100 glucose units) was determined by proton nuclear magnetic resonance. Disposable dialyzers based on cellulose mixed esters membrane MWCO $50 \mathrm{~kg} / \mathrm{mol}$ were obtained from Sigma-Aldrich (Buchs, Switzerland). DMSO- $d_{6}$ and methanol- $d_{4}$ were obtained from Cambridge Isotope Laboratories (Andover, USA).
2.2. Preparation and Degradation of the Microspheres. 2.2.1. Preparation of the Microspheres. To analyze the nature and the quantity of both the soluble and the insoluble degradation products of dexHEMA microspheres with different cross-link densities, different batches of microspheres (DS 8, 12, 20; fixed water content of 50\%) were prepared at $100 \mathrm{~g}$ scale (yielding $1.2 \mathrm{~g}$ of dry dex-HEMA microspheres). To collect enough sample material to accurately determine the mass loss and to follow the evolution of the chemical composition, the mechanical strength, and the morphology of the microspheres in time, one batch of microspheres (DS 12, initial water content $50 \%(\mathrm{w} / \mathrm{w}))$ was prepared at $1 \mathrm{~kg}$ scale (yielding $12 \mathrm{~g}$ of dry dex-HEMA microspheres). The preparation of the microspheres at 100 $\mathrm{g}$ and $1 \mathrm{~kg}$ scale was essentially done as described elsewhere. ${ }^{22}$ In detail, for a $100 \mathrm{~g}$ batch, $12 \mathrm{~g}$ of a $10 \%$ solution of dex-HEMA (DS 8, 12, or 20) in $10 \mathrm{mM}$ phosphate buffered saline $\mathrm{pH} 7.0$ (PBS) was added to a solution of PEG in PBS (22.4 g, 40\% (w/w)), and PBS was added to a final mass of $100 \mathrm{~g}$, resulting in a PEG/dex-HEMA volume ratio of 40:1, based on PEG/dex-HEMA phase diagrams. ${ }^{14}$ The PEG/dexHEMA/water mixture was emulsified for $55 \mathrm{~min}$ at $1500 \mathrm{rpm}$ using a three-bladed impeller ( $2 \mathrm{~cm}$ in diameter). Next, $4 \mathrm{~mL}$ of TEMED solution $(20 \%(\mathrm{v} / \mathrm{v}), \mathrm{pH}$ adjusted to 7.0 with $4 \mathrm{M}$ hydrochloric acid) was added, and stirring was continued for $5 \mathrm{~min}$. The stirring rate was set to $500 \mathrm{rpm}, 2.7 \mathrm{~mL}$ of $50 \mathrm{mg} / \mathrm{mL}$ KPS solution was added, and stirring was continued for 1 more minute. Next, the stirring was stopped and the emulsion was incubated at room temperature for $60 \mathrm{~min}$ to polymerize the dextran grafted HEMA groups. The microspheres were purified with water by five centrifugation $(3200 \mathrm{~g}, 20 \mathrm{~min})$ and washing steps ( $15 \mathrm{~mL}$ of water). Finally, the microspheres were resuspended in a minimal volume of water and freeze-dried. For the preparation at 1 $\mathrm{kg}$ scale, 10-fold larger amounts were used. The emulsification was performed in a $2 \mathrm{~L}$ reaction vessel with a three-bladed impeller $(4.5$ $\mathrm{cm}$ in diameter) and a stirring speed of $1500 \mathrm{rpm}$. Average particle diameter and size distributions of the microspheres were measured with a Malvern Mastersizer 2000 (Malvern instruments Ltd., Worcestershire, United Kingdom) with water as eluent. After preparation, the methacrylate conversion was determined as described previously. ${ }^{33}$

2.2.2. Degradation of dex-HEMA Microspheres. Freeze-dried microspheres (DS 12, $2 \mathrm{~g}$ ) were rehydrated in $5 \mathrm{~mL}$ of PBS containing $0.02 \% \mathrm{NaN}_{3}(\mathrm{pH} 7.4)$ and transferred into a disposable dialyzer. Six dialyzers, each filled with $5 \mathrm{~mL}$ of microsphere suspension, were transferred into a vial containing $500 \mathrm{~mL}$ of buffer $(10 \mathrm{mM} \mathrm{PB}, 100$ $\mathrm{mM} \mathrm{NaCl}, 0.02 \% \mathrm{NaN}_{3}, \mathrm{pH} 7.4$ ) and subsequently incubated at $37^{\circ} \mathrm{C}$. At regular time intervals, one of the dialyzers was removed and the entire incubation buffer was refreshed. The concentration of dextran in the removed incubation buffer was determined with SEC. Cumulative release curves were obtained by summation of the amount of dextran released at each time point. The microspheres from the removed dialyzer were analyzed using a light microscope (microscope with D12 digital camera, Olympus Optical Co. Shibuya, Tokyo, Japan). Hereafter, the microspheres were extensively washed with water $(15 \mathrm{~mL}$, five times centrifugation, $3200 \mathrm{~g}, 20 \mathrm{~min}$ ) and freeze-dried. The mass of the freezedried microspheres was determined. The freeze-dried microspheres were analyzed with Fourier transformed infrared spectroscopy (FT-IR) and X-ray photoelectron microscopy (XPS). The mechanical strength of the microspheres after rehydration was analyzed with a micromanipulation technique as described by Stenekes et al. ${ }^{34}$

2.2.3. Quantification and Analysis of Degradation Products. To collect, quantify, and identify the water-soluble and water-insoluble degradation products, dex-HEMA microspheres (DS 8, 12, and 20) were hydrolyzed under accelerated conditions. In detail, $240 \mathrm{mg}$ of freezedried microspheres was suspended in $4 \mathrm{~mL}$ of $0.1 \mathrm{M} \mathrm{NaOH}$ and incubated for 5 days at $70{ }^{\circ} \mathrm{C}$. Next, the suspension ( $\mathrm{pH}$ adjusted 7.0 with $0.1 \mathrm{M} \mathrm{HCl}$ ) was centrifuged $(3200 \mathrm{~g}, 5 \mathrm{~min})$, and the supernatant (fraction A) and the insoluble residue (fraction B) were separated. Fraction A was freeze-dried until about $2 \mathrm{~mL}$ remained, and subsequently $8 \mathrm{~mL}$ of methanol was added. The sample was centrifuged to separate the methanol-soluble part (A2) from the methanol-insoluble 
part (A1). Sample A1 was washed several times with methanol to remove residual methanol-soluble degradation products, dried, and weighed. Sample A2 was dried in air and weighed. The molecular weight and molecular weight distribution of the polymers in sample A1 dissolved in water and A2 dissolved in DMF were determined using SEC (see section 2.3.1), and their chemical composition was established via NMR (see section 2.3.4).

Fraction B was washed several times with water to remove residual water-soluble compounds. Next, $16 \mathrm{~mL}$ of methanol was added to the water-insoluble part (B) to obtain a methanol-soluble (B1) and a methanol-insoluble fraction (B2). The methanol-insoluble fraction (B2) was washed several times with methanol, dried, weighed, and analyzed by FT-IR. The methanol in fraction B1 was almost completely removed (room temperature) until about $1 \mathrm{~mL}$ of this solution remained. The molecular weight and the molecular weight distribution of the polymer in this fraction were determined with SEC as described in section 2.3.1. Next, the samples were further dried in air and the chemical composition was established with FT-IR (see section 2.3.6).

2.2.4. Analysis and Release of HEMA-DMAP. Ten milligram microspheres (DS 8, 12, or 20) were incubated at room temperature in $5 \mathrm{~mL}$ of $10 \mathrm{mM} \mathrm{NH}_{3}$ solution ( $\mathrm{pH}$ 9) at room temperature for 3 days. At regular time intervals, the suspension of degrading microspheres was centrifuged $(3200 \mathrm{~g}, 20 \mathrm{~min})$, and the supernatant was analyzed by HPLC (see section 2.3.2) and by ESI-MS (see section 2.3.3). As a control, $10 \mathrm{mg}$ of dex-HEMA was incubated under the same conditions, and the concentration of HEMA-DMAP was determined via HPLC (see section 2.3.2)

2.3. Analyses. 2.3.1. Size Exclusion Chromatography. SEC analyses of the water-soluble degradation products were performed with a system consisting of an HPLC pump series 200, a vacuum degasser series 200, an autosampler series 200, a column LC 101 oven, a differential refractometer PL-RI 800 (all Perkin-Elmer Instruments, Norwalk, USA), and two thermostated $\left(35^{\circ} \mathrm{C}\right)$ Shodex KB-800 series columns (OHpak KB-800P, $6 \mathrm{~mm} \times 50 \mathrm{~mm}$, guard column; OHpak KB-806M $8 \mathrm{~mm} \times$ $300 \mathrm{~mm}$, exclusion limit $2 \times 10^{7}$; Showa Denko, Tokyo, Japan). The flow rate was $0.7 \mathrm{~mL} / \mathrm{min}$, and the mobile phase was an aqueous solution of $20 \mathrm{mM}$ phosphate buffer $\mathrm{pH} 7.0$ also containing $200 \mathrm{mM}$ $\mathrm{NaCl}$. The columns were calibrated with dextran standards of known molecular weight and narrow molecular weight distribution (Fluka Chemie AG). The chromatograms were recorded and analyzed with the data acquisition system Perkin-Elmer Totalchrom (Perkin-Elmer Instruments, Norwalk, USA).

The methanol-soluble degradation products were analyzed using the same HPLC system. The PLgel $5 \mu \mathrm{m}$ MIXED-C columns (Polymer Laboratories Inc., Amherst, USA) were thermostated at $50{ }^{\circ} \mathrm{C}$. The flow rate was $0.7 \mathrm{~mL} / \mathrm{min}$, and the mobile phase consisted of DMF with $0.02 \mathrm{M} \mathrm{LiCl}$. The columns were calibrated with PEG standards of known molecular weight and narrow molecular weight distribution (Fluka Chemie AG).

2.3.2. Reversed-Phase High Performance Liquid Chromatography. Reversed-phase HPLC was used to determine the methacrylate conversion of the microspheres and to determine the concentration of HEMA and HEMA-DMAP in the release samples (section 2.2.4). The HPLC system consisted of a pump series 200, a vacuum degasser series 200 , an autosampler series 200, a column LC 101 oven, and a UV detector series 200 (all Perkin-Elmer Instruments, Norwalk, USA) and a thermostated $\left(35^{\circ} \mathrm{C}\right) \mathrm{RP}-18$ column (Symmetry C18, $4.6 \times 150 \mathrm{~mm}$ ) with an $8 \times 3 \mathrm{~mm}$ precolumn (all Waters, Ireland). The flow rate was $1.0 \mathrm{~mL} / \mathrm{min}$, and a mobile phase of water/acetonitrile 10/90 v/v (adjusted to $\mathrm{pH} 2.0$ with perchloric acid) was used. A calibration curve was obtained by injecting $50 \mu \mathrm{L}$ of $0.5-25 \mu \mathrm{g} / \mathrm{mL}$ MA or HEMA. The concentration of HEMA-DMAP was determined using a calibration curve of DMAP obtained by injecting $50 \mu \mathrm{L}$ in the concentration range $0.5-25 \mu \mathrm{g} / \mathrm{mL}$. The chromatograms were recorded and analyzed with the data acquisition system Totalchrom (Perkin-Elmer Instruments, Norwalk, USA).
2.3.3. Electrospray Mass Spectrometry. The samples obtained by degradation of microspheres in an aqueous $\mathrm{NH}_{3}$ solution (see section 2.2.4) were injected on a tandem quadrupole mass analyzer Micromass Quattro LC (Micromass, Cheshire, United Kingdom). The cone voltage was $30 \mathrm{~V}$, the capillary voltage was $2.8 \mathrm{kV}$, the scan range was $\mathrm{m} / \mathrm{z}$ $0-1500$, the flow rate was $4 \mu \mathrm{L} / \mathrm{min}$, the source temperature was 60 ${ }^{\circ} \mathrm{C}$, and the desolvation temperature was $80^{\circ} \mathrm{C}$. Positively charged ions were produced using an electrospray probe. Calibration was done with a mixture of $96 \mathrm{mg}$ of $\mathrm{NaI}$ and $2.5 \mathrm{mg}$ of CsI in $50 \mathrm{~mL}$ of 2-propanol. For MS/MS analysis, the collision energy was $25 \mathrm{eV}$, and argon was used as the collision gas. The mass spectra were analyzed using Masslynx Software (Micromass, Cheshire, United Kingdom). The exact mass measurements were carried out with a Micromass LC ToF (Micromass, Cheshire, United Kingdom) using nano-electrospray ionization. Cone voltage was $30 \mathrm{~V}$, and capillary voltage $1.2 \mathrm{kV}$. Calibration was performed with PEG 400 in acetonitrile/water containing $20 \mathrm{mM}$ ammonium acetate.

2.3.4. ${ }^{1} H$ NMR Spectroscopy. NMR spectra were recorded with a Gemini $300 \mathrm{MHz}$ spectrometer (Varian associates Inc. NMR instruments, Palo Alto, CA). Approximately $30 \mathrm{mg}$ of material was dissolved in $0.8 \mathrm{~mL}$ of a suitable solvent. For measurements in methanol, the signal at $3.31 \mathrm{ppm}$ was used as the reference line, whereas in DMSO$d_{6} / \mathrm{D}_{2} \mathrm{O}(7: 1)$, the central DMSO line was set at $2.5 \mathrm{ppm}$.

2.3.5. Micromanipulation. The mechanical properties of the microspheres were measured by a micromanipulation technique. Briefly, a single microsphere was compressed between two parallel surfaces to a certain deformation. Simultaneously, a force transducer measured the force being imposed on the microspheres as a function of the applied deformation. The details of this technique are described elsewhere. ${ }^{34-38}$

2.3.6. Infrared Spectroscopy. The Fourier transformed infrared spectra (FT-IR) of the freeze-dried microspheres and the water-insoluble degradation products (fractions B1 and B2 after drying; section 2.2.3) were recorded in transmission mode on a Bio-Rad FTS6000 FT-IR spectrometer with Win-IR Pro software (Cambridge, MA). Spectra were obtained from a $\mathrm{KBr}$ tablet compressed at 10 tons with a hydraulic press. Each tablet contained $2 \%(\mathrm{w} / \mathrm{w})$ of microspheres or reference polymer (dextran, pHEMA, or a mixture of both). Scans (128) were co-added at $2 \mathrm{~cm}^{-1}$ resolutions at a scan speed of $0.16 \mathrm{~cm} / \mathrm{s}(5 \mathrm{kHz}$ laser modulation). The spectra were corrected for water vapor at $3700-$ $3800 \mathrm{~cm}^{-1}$. PHEMA was obtained by polymerization of HEMA $(4 \mathrm{~g}$, $30.1 \mathrm{mmol})$ with AIBN (0.52 g, $3.2 \mathrm{mmol})$ in $40 \mathrm{~mL}$ of freshly distilled dioxane at $80^{\circ} \mathrm{C}$ for $2 \mathrm{~h}$. After this, pHEMA was precipitated in hexane and dried under vacuum at $40{ }^{\circ} \mathrm{C}$. The spectra obtained from the pHEMA and dextran (different mass ratios) were used to calculate the composition of the different microsphere samples. The composition of degraded microspheres was determined by comparing the peak heights to a reference sample of a mixture of pHEMA and dextran of a known composition.

2.3.7. X-ray Photoelectron Spectroscopy. To analyze the surface composition of nondegraded and degraded microspheres, X-ray photoelectron spectroscopy (XPS) analyses were performed. XPS is a surface sensitive technique, with a probing depth in the range of 1-5 $\mathrm{nm}$. The XPS C1s spectra were obtained using a Vacuum Generators CLAM-2 hemispherical analyzer operating at $100 \mathrm{eV}$ pass energy. A $\mathrm{Mg} \mathrm{K} \alpha$ source (Vacuum Generators twin-anode XR2E2) was used at $120 \mathrm{~W}$. The angle between the surface and the analyzer axis was $15^{\circ}$, and the angle between the analyzer and the $\mathrm{X}$-ray source axis was $33.5^{\circ}$. For XPS analysis, the freeze-dried dex-HEMA micropheres were hydrated in a small amount of water, and the resulting paste was spread onto the XPS sample plate and dried in air. Samples of pHEMA, dextran, and degraded microspheres were obtained by powder compression with a pressure of $10.4 \mathrm{~kg} / \mathrm{cm}^{2}$ using an infrared tablet press. The $\mathrm{C} 1 \mathrm{~s}$ spectra were subsequently recorded three times to check for the absence of sample degradation due to radiation and charging stability during analysis. The spectra obtained from the pHEMA and dextran (different mass ratios) were used to calculate the surface composition of the different microsphere samples. Assuming that the outer layer of 
Table 1. Particle Size and Methacrylate Conversion of Microspheres $^{a}$

\begin{tabular}{rccc}
\hline DS & $\begin{array}{c}\text { process } \\
\text { scale }\end{array}$ & $\begin{array}{c}\text { volume mean } \\
\text { diameter } \\
(\mu \mathrm{m})\end{array}$ & $\begin{array}{c}\text { methacrylate } \\
\text { conversion } \\
(\%)\end{array}$ \\
\hline 8 & $100 \mathrm{~g}$ & $19 \pm 1$ & $90 \pm 1$ \\
12 & $100 \mathrm{~g}$ & $20 \pm 1$ & $92 \pm 1$ \\
12 & $1 \mathrm{~kg}$ & $23 \pm 3$ & $94 \pm 1$ \\
20 & $100 \mathrm{~g}$ & $32 \pm 2$ & $90 \pm 1$ \\
\hline
\end{tabular}

a The values in this table are the average \pm standard deviation obtained from three independent measurements.

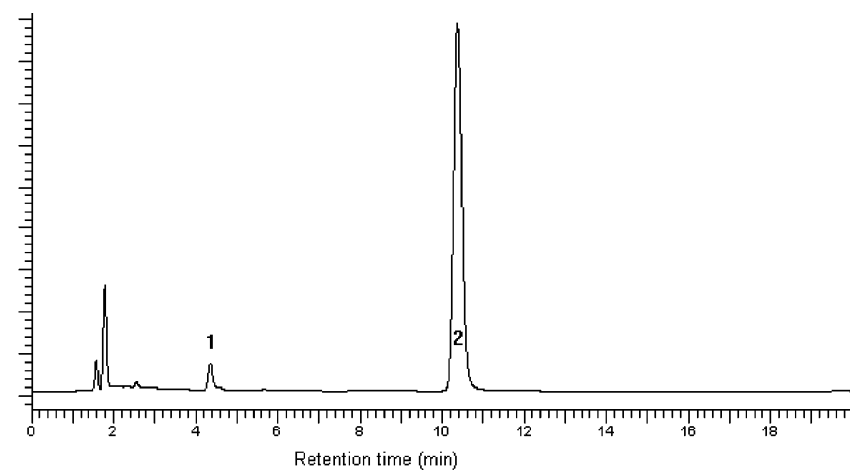

Figure 1. RP-HPLC chromatogram of an accelerated degradation sample $(t=1 \mathrm{~h}, \mathrm{pH}=9)$ containing HEMA-DMAP (1) and HEMA (2) and buffer salts (peaks eluted before $\mathrm{rt}=2 \mathrm{~min}$ ).

a microsphere is a mixture of pHEMA and dextran, the resulting signal intensity $I\left(E_{\mathrm{tot}}\right)$ can be considered as a superposition of the pHEMA and dextran signals according to:

$$
I(E)_{\mathrm{tot}}=c I(E)_{\mathrm{dexran}}+(1-c) I(E)_{\mathrm{pHEMA}}
$$

In this equation, $I(E)_{\text {dextran }}$ and $I(E)_{\text {pHEMA }}$ are the signal intensities of dextran and pHEMA, respectively, $E$ is the binding energy of the electrons, and $c$ is the fraction of dextran in the mixture.

\section{Results and Discussion}

3.1. Characterization of the Prepared Microspheres and Release of HEMA and HEMA-DMAP. In Table 1, the water content, particle size, and methacrylate conversion of the different microsphere formulations are given. The volume mean diameter ranged between 19 and $32 \mu \mathrm{m}$.

The dex-HEMA microspheres were larger than the microspheres previously prepared by Franssen et al. $(10 \mu \mathrm{m}),{ }^{22}$ which might be attributed to the difference in manufacturing scale. The microspheres in ref 22 were prepared at a $5 \mathrm{~g}$ scale, and emulsification was performed with a vortex (at $1500 \mathrm{rpm}$ ). In the present study, the microspheres were prepared at $100 \mathrm{~g}$ scale in a reactor equipped with an impeller stirring at $1500 \mathrm{rpm}$.
The use of a larger amount of reaction mixture (100 g) and different dimensions of the reaction vessel can result in a lower shear stress per volume emulsion, which in turn results in larger spheres. ${ }^{19}$ In agreement with previous findings, the methacrylate conversion exceeded $90 \%$ for all formulations. ${ }^{33}$

HPLC analysis of the water-soluble degradation products samples revealed besides the presence of HEMA ( $\mathrm{rt}=10.5$ $\mathrm{min}$ ) also that of another molecule ( $\mathrm{rt}=4.4 \mathrm{~min}, \lambda_{\max }=289$ nm) (Figure 1).

It was found that both compounds were released from the microspheres at the same rate during 2 days of incubation in a $10 \mathrm{mM} \mathrm{NH}_{3} \mathrm{pH} 9$ at room temperature, which suggests that this compound, like HEMA, was coupled to dextran via a carbonate ester. The exact mass of this compound as established with LC/MS/MS was 252.1552, which is in agreement with the bruto formula $\mathrm{C}_{13} \mathrm{H}_{20} \mathrm{~N}_{2} \mathrm{O}_{3}$. This suggests that this molecule may be the protonated reaction product formed by the addition reaction of HEMA $\left(\mathrm{C}_{6} \mathrm{H}_{10} \mathrm{O}_{3}, M_{\mathrm{w}} 130 \mathrm{~g} / \mathrm{mol}\right)$ to DMAP $\left(\mathrm{C}_{7} \mathrm{H}_{10} \mathrm{~N}_{2}, M_{\mathrm{w}} 122 \mathrm{~g} / \mathrm{mol}\right)$, which is used as a catalyst for the coupling of HEMA-imidazole carbamate (HEMA-CI) to dextran. ${ }^{32}$ Figure 2 shows the MS/MS spectrum and the possible structure of the HEMA-DMAP molecule, as derived from this spectrum. The ions in this MS/MS spectrum at $\mathrm{m} / \mathrm{z}, 209$ and 123 in the MS/MS spectrum are either formed by cleavage of, respectively, ethanal from the HEMA-DMAP adduct ([M + $\mathrm{H}-44]^{+}$) and further cleavage of methacrylic acid from the ion $m / z 209$ or formed by immediate cleavage of HEMA from HEMA-DMAP $\left([\mathrm{M}+\mathrm{H}-130]^{+}\right)$. The ion at $\mathrm{m} / \mathrm{z} 136$ is formed by cleavage of acrylic acid from the ion at $m / z 209$.

Most probably, the reaction of HEMA with DMAP to form HEMA-DMAP is based on the Baylis-Hillman reaction of an activated alkene or alkyne with an aldehyde or ketone (Scheme 1). ${ }^{39}$ Baylis-Hillman reactions usually require Lewis bases, such as tertiary amines, for example, 1,4-diazabicyclo$[2,2,2]$ octane (DABCO) and DMAP, as catalysts. ${ }^{39,40}$ Likely, the HEMA-DMAP adduct (Scheme 2) is an intermediate of the Baylis-Hillman reaction, which is stabilized by the intramolecular salt-bridge that is formed between the positively charged quaternary $\mathrm{N}$-atom and the negatively charged enolate anion.

3.2. Degradation of dex-HEMA Microspheres and Analysis of Degradation Products. To study the in vitro degradation of dex-HEMA microspheres, the mass loss and dextran release were determined for microspheres of dex-HEMA DS 12 (water content $50 \%$ ) at $\mathrm{pH} 7.4$ and $37^{\circ} \mathrm{C}$ (Figure 3).

This figure shows that the microspheres lost $94 \%$ of their mass in 6 months. After this period, no further degradation was observed (results not shown), leaving a solid residue of $6 \%$ of the initial mass of the microspheres. As mentioned in the Introduction, the expected degradation products of the microspheres are dextran and pHEMA. It is also shown in Figure 3
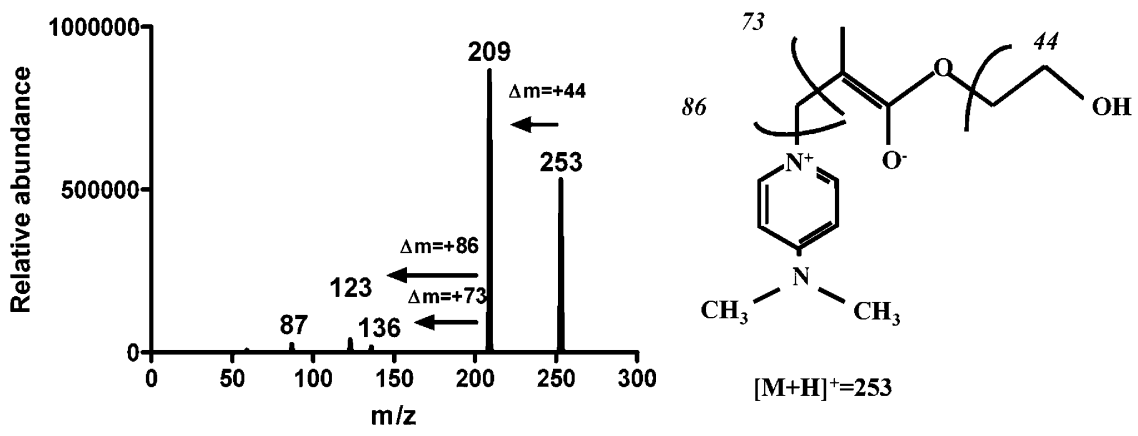

Figure 2. The MS/MS spectrum of the Baylis-Hillman intermediate of HEMA and DMAP (right). 
Scheme 1. Bayliss-Hillman Reaction of a Methyl Vinyl Ketone with an Aryl Aldehyde Catalyzed by DMAP<smiles>C=CC(C)=O</smiles><smiles>CN(C)c1ccc(C=CC2CC2)cc1</smiles><smiles>CCCCCCC</smiles><smiles>[CH][C+]=CCC</smiles><smiles>C=C(C(C)=O)C(O)Br</smiles>

Scheme 2. Bayliss-Hillman Reaction of DMAP with HEMA

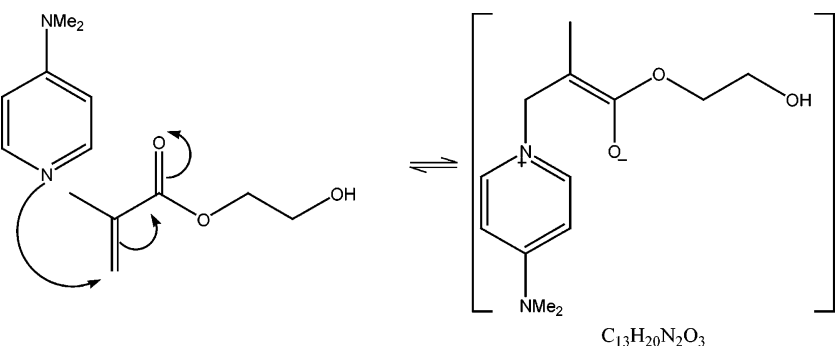

that dextran was released quantitatively within 6 months, which suggests that the solid residue consists of pHEMA. In addition, it can be calculated that the expected mass loss for microspheres of dex-HEMA DS 12 after complete release of dextran is $91 \%$. This might indicate that, during the degradation besides dextran, a small amount of water-soluble pHEMA is released.

The chemical composition of the solid residue present at 2.8 and 5.7 months was analyzed with FT-IR (Figure 4a) and compared to that of nondegraded microspheres. The most significant bands resolved in the spectrum of the nondegraded microspheres are $1726 \mathrm{~cm}^{-1}[v(\mathrm{C}=\mathrm{O})], 1150 \mathrm{~cm}^{-1}[v(\mathrm{C}-\mathrm{O})]$, $1162 \mathrm{~cm}^{-1}\left[\gamma\left(\mathrm{CH}_{3}\right), \tau(\mathrm{OH})\right], 1050 \mathrm{~cm}^{-1}[\delta(\mathrm{C}-\mathrm{OH})]$, and 980 $\mathrm{cm}^{-1}[v(\mathrm{C}-\mathrm{O})$ and $\delta(\mathrm{C}-\mathrm{OH})]$, in which $v$ is bond stretching, $\tau$ is torsion, $\delta$ is bending, and $\gamma$ is rocking. ${ }^{41-43}$ It is clearly visible that in the spectra of the solid residue that remained at 2.8 and 5.7 months of degradation the intensity of the band at $1726 \mathrm{~cm}^{-1}$ had increased and the peaks at $1074 \mathrm{~cm}^{-1}[v(\mathrm{C}-$ $\mathrm{O})$, alcohol] and $1021 \mathrm{~cm}^{-1}[v(\mathrm{C}-\mathrm{O})$ ester] were more resolved as compared to those in the spectra of nondegraded microspheres. To enable the interpretation of these data properly, FTIR spectra of pHEMA, dextran, and different mixtures of dextran and pHEMA were taken (Figure 4b).

With increasing mass ratio of pHEMA, the intensity of the ester band at $1726 \mathrm{~cm}^{-1}[v(\mathrm{C}=\mathrm{O})]$ increases, whereas the peak intensity of the cyclic alcohols in dextran $\left(1050 \mathrm{~cm}^{-1}[\delta(\mathrm{C}-\right.$ $\mathrm{OH})]$ ) decreases. Therefore, by combining the results of Figure $4 \mathrm{a}$ and $\mathrm{b}$, it can be concluded that the insoluble degradation

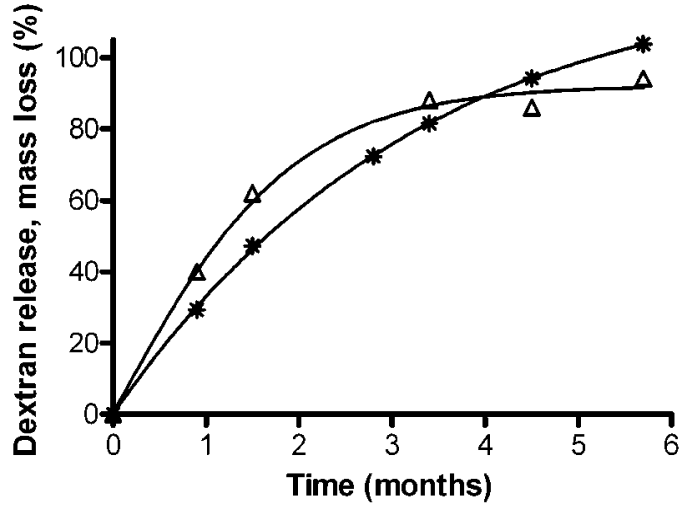

Figure 3. Dextran release $\left({ }^{*}\right)$ and mass loss $(\triangle)$ of dex-HEMA microspheres (DS 12; initial water content $50 \%$ ) incubated at $37^{\circ} \mathrm{C}$ and $\mathrm{pH} 7.4$ as a function of time. products are enriched in pHEMA. Quantitative analysis of the FT-IR spectrum of the water-insoluble material that was present after 6 months indicated that this material consisted essentially of pHEMA $(89 \pm 6 \%)$. These FT-IR analyses were not sensitive enough to detect trace amounts of dextran in the remaining insoluble degradation products.

Light microscopy revealed that the water-insoluble residue consisted of spherical particles. The size and shape of these particles was not significantly different from that of the nondegraded microspheres (Figure 5). However, during degradation the particles became more transparent than the nondegraded microspheres, which implies that the difference in refractive index between these hydrated microspheres and

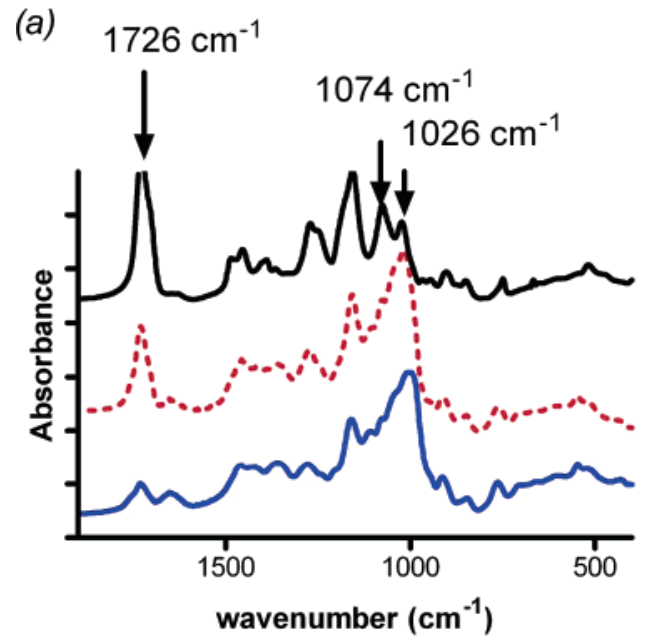

(b) $1726 \mathrm{~cm}^{-1}$

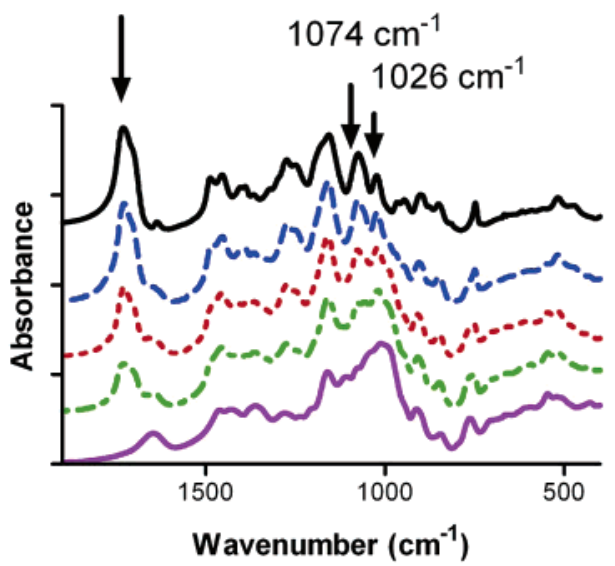

Figure 4. FT-IR spectra in the region $1900-400 \mathrm{~cm}^{-1}$ of nondegraded microspheres DS 12 (blue line), and degraded microspheres after 2.8 months (red line) and 5.7 months (black line) of incubation $\left(\mathrm{pH} 7.4,37^{\circ} \mathrm{C}\right)(\mathrm{a}) . \mathrm{FT}-\mathrm{IR}$ spectra of pHEMA and dextran, as well as their physical mixtures in the region between 1900 and $400 \mathrm{~cm}^{-1}$. From top to bottom: pHEMA/dextran 100/0 (black line), 80/20 (blue line), 50/50 (red line), 40/60 (green line), 0/100 (purple line) (w/w) (b). 

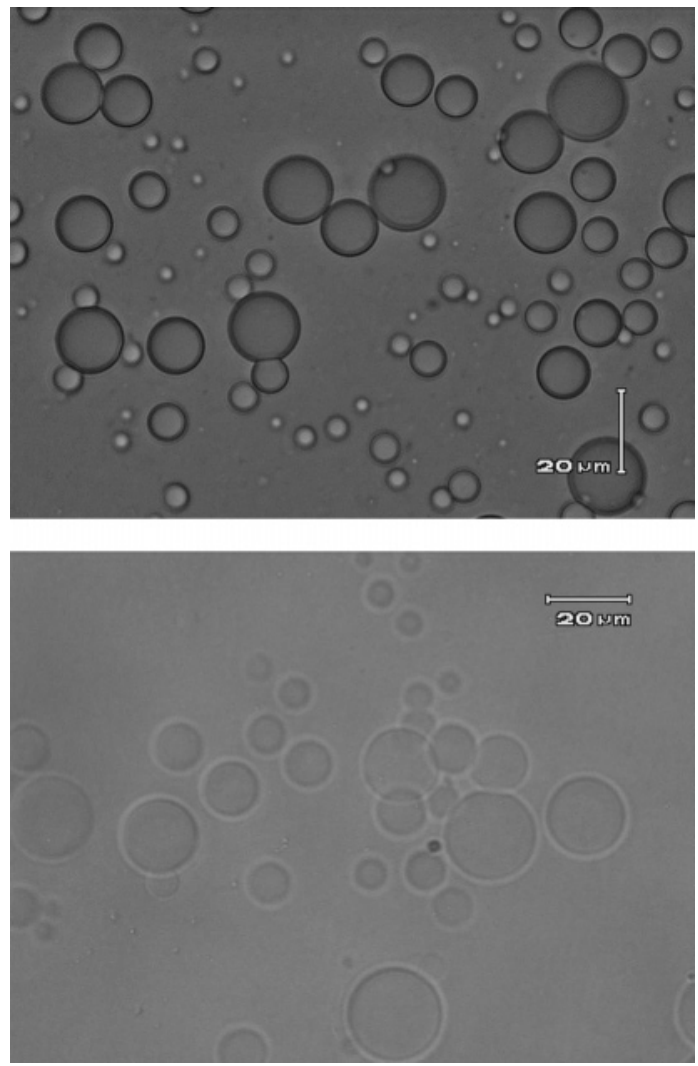

Figure 5. Microscopy image of microspheres (DS 12) in phosphate buffer (10 mM, $\left.100 \mathrm{mM} \mathrm{NaCl}, 0.02 \% \mathrm{NaN}_{3}, \mathrm{pH}=7.4\right)$. Top: nondegraded microspheres. Bottom: degraded microspheres (DS 12 , 5.7 months, $\mathrm{pH}=7.4,37^{\circ} \mathrm{C}$ ).

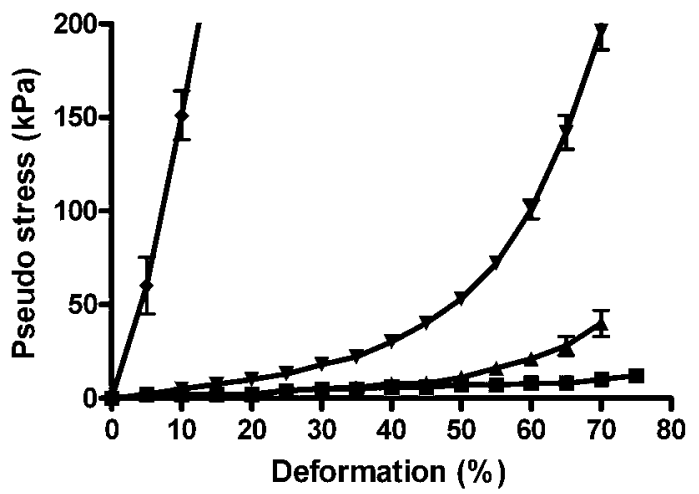

Figure 6. Micromanipulation compression profiles of dex-HEMA microspheres at $t=0(\bullet), 1(\nabla), 1.5(\mathbf{\Lambda})$, and $2.8(\boldsymbol{\square})$ months.

surrounding medium (water) had decreased. This can be attributed to a higher extent of hydration of the degraded microspheres as a result of the release of dextran (Figure 3).

The mechanical strength of the microspheres as a function of the degradation time was investigated by the micromanipulation technique. Figure 6 shows that the mechanical rigidity of the microspheres represented by the pseudo elasticity modulus (calculated from the initial slope of the pseudo stress strain curves $\left.^{34}\right)$ drastically decreased in time, from $1.4 \pm 0.1 \mathrm{MPa}(t$ $=0)$ to $0.0070 \pm 0.0005 \mathrm{MPa}(t=2.8$ months $)$.

This can be ascribed to hydrolysis of the cross-links in the dex-HEMA network, resulting in a decrease of the cross-link density and thereby of the mechanical strength. ${ }^{34}$ After 3 months, the compression force acting on the microspheres was below the detection level of the micromanipulation force transducer. This indicates that at this time point when $70 \%$ of the total (a)

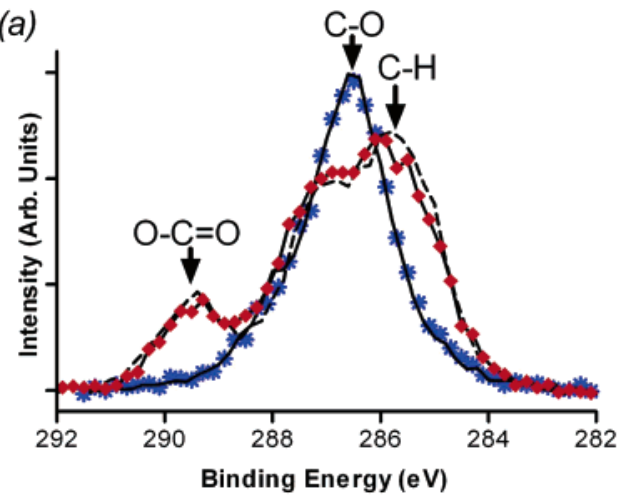

(b)

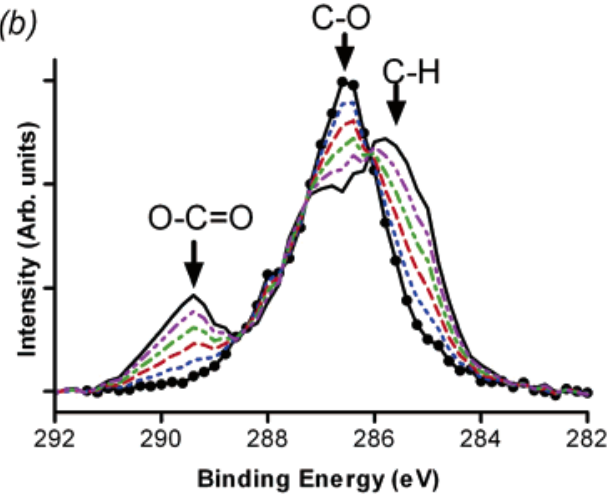

Figure 7. XPS C1s spectrum of pHEMA (- - ), dextran (-), nondegraded dex-HEMA microspheres of DS $12\left({ }^{*}\right)$, and degraded dexHEMA microspheres of DS 12 (5.7 months, pH 7.4, $\left.37^{\circ} \mathrm{C}\right)(\diamond)(\mathrm{a})$; and XPS C1s spectrum of pHEMA (black line), dextran (--), and mixtures of pHEMA and dextran in ratios 20/80 (blue line), 40/60 (red line), 60/40 (green line), and 80/20 (purple line) (b).

amount of dextran has been released from the microspheres, they essentially had lost their mechanical strength.

The surface composition of the microspheres was investigated with XPS. Figure 7 shows the C1s spectra of nondegraded dexHEMA microspheres, the insoluble residue isolated at 5.7 months, pHEMA, and dextran (Figure 7a), and different mixtures of pHEMA and dextran (Figure 7b).

In the spectrum of dextran and the nondegraded microspheres, the peaks originating from $\mathrm{C}-\mathrm{O}$ of the alcohols and glycosidic bonds in dextran are clearly visible (Figure 7a,b). In the spectrum of pHEMA and the insoluble degradation products, $\mathrm{O}-\mathrm{C}=\mathrm{O}$ (of the ester group present in pHEMA), $\mathrm{C}-\mathrm{O}$ (present in pHEMA (partly overlapped by $\mathrm{C}-\mathrm{H}$ signal of pHEMA)), and $\mathrm{C}-\mathrm{H}$ groups of pHEMA (Figure $7 \mathrm{a}, \mathrm{b}$ ) are observed. ${ }^{44,45}$ In Figure $7 b$, the calculated spectra of different mixtures of dextran and pHEMA are shown. As expected, with increasing ratios $\mathrm{pHEMA} /$ dextran, the peaks of $\mathrm{O}-\mathrm{C}=\mathrm{O}$ and $\mathrm{C}-\mathrm{H}$ become more apparent.

When the peak intensities in the spectrum of the nondegraded microspheres (Figure 7a) were fitted with eq 1 (section 2.3.7), the calculated mass percentage of pHEMA in the outer layer of nondegraded microspheres was $5 \pm 4 \%$. Provided that pHEMA and dextran were homogeneously distributed in the outer layer of the microspheres, for nondegraded microspheres prepared from dex-HEMA DS 12, a mass percentage of 9\% pHEMA was expected. The calculated composition is in good agreement with the expected composition and with the bulk composition as calculated from the FT-IR spectra.

Fitting the peak intensities of the insoluble residue that was present at 5.7 months revealed a pHEMA content of more than $91 \pm 6 \%$. FT-IR analysis showed that the insoluble residue 
Table 2. Solubility, Identity, and Mass Percentage of Different Degradation Products of dex-HEMA Microspheres (DS 8, 12, or 20)

\begin{tabular}{ccccrrr}
\hline fraction & water- & methanol- & chemical & \multicolumn{3}{c}{ mass percentage (\%) } \\
\cline { 5 - 7 } (see section 2.2.3) & soluble & soluble & composition & DS 8 & DS 12 & DS 20 \\
\hline A1 & + & - & dextran & 99 & 96 & 87 \\
A2 & + & + & LMW pHEMA & 1 & 1 & $<1$ \\
B1 & - & - & HMW pHEMA & $<1$ & $<1$ & 7 \\
B2 & - & - & insoluble pHEMA ${ }^{b}$ & 4 & 14 \\
\hline
\end{tabular}

$a+=$ soluble, $-=$ insoluble, LMW $=$ low molecular weight, HMW $=$ high molecular weight. ${ }^{b}$ Solvent removal was incomplete due to inclusion of solvent during drying.

Table 3. Molecular Weights of Degradation Products from Various Microspheres

\begin{tabular}{cccccc}
\hline DS & fraction & $\begin{array}{c}\text { chemical } \\
\text { composition }\end{array}$ & $\begin{array}{c}M_{\mathrm{n}} \\
(\mathrm{kg} / \mathrm{mol})\end{array}$ & $\begin{array}{c}M_{\mathrm{w}} \\
(\mathrm{kg} / \mathrm{mol})\end{array}$ & PDI $^{a}$ \\
\hline \multirow{2}{*}{8} & A2 & LMW pHEMA & 16 & 20 & 1.2 \\
& B1 & HMW pHEMA & 65 & 103 & 1.6 \\
12 & A2 & LMW pHEMA & 16 & 28 & 1.7 \\
& B1 & HMW pHEMA & 82 & 163 & 2.0 \\
20 & A2 & LMW pHEMA & 14 & 18 & 1.3 \\
& B1 & HMW pHEMA & 26 & 48 & 1.8 \\
\hline
\end{tabular}

${ }^{a} \mathrm{PDI}=$ polydispersity index.

consisted for $89 \pm 5 \%$ of pHEMA. This suggests that also for these insoluble residues their surface composition is similar to their bulk composition and that they essentially consist of pHEMA.

3.3. Analysis of Mass Fraction and Composition of WaterSoluble and Water-Insoluble Degradation Products. The composition and mass fraction of the water-soluble products and the water-insoluble residue of microspheres with different cross-link densities (obtained by polymerization of dex-HEMA of DS $8,12,20)$, degraded under accelerated conditions (0.1 $\mathrm{M} \mathrm{NaOH}, 70{ }^{\circ} \mathrm{C}, 3$ days), were established (Table 2).

It was shown by NMR that the water-soluble fraction (A) mainly consisted of dextran and a small fraction of water-soluble pHEMA. As indicated in Table 2, the mass percentage of dextran (A1) and water-soluble pHEMA (A2) was, respectively, $86-99 \%$ and $<1 \%$. (The mass percentage of dextran recovered in the water-soluble degradation products is consistent with the expected amount of dextran in the microspheres (87-94\% $\mathrm{w} / \mathrm{w})$.) The water-insoluble degradation products (B) consisted of a small fraction of methanol-soluble pHEMA (B1; <1\% w/w, independent of the cross-link density of the microspheres) and methanol-insoluble pHEMA (B2), which increased with DS from 4 to $14 \% \mathrm{w} / \mathrm{w}$ (Table 2). This indicates that pHEMA is mainly recovered as methanol-insoluble product.

The number average molecular weight of the water-soluble pHEMA (A2) was between 14 and $16 \mathrm{~kg} / \mathrm{mol}$ with a polydispersity between 1.2 and 2.0 (Table 3 ), which is consistent with previous observations by Weaver et al. ${ }^{31}$

For dextran in fraction A1, it was found that, independent of the formulation, $M_{\mathrm{n}}=20 \mathrm{~kg} / \mathrm{mol}$, and $M_{\mathrm{w}}=37 \mathrm{~kg} / \mathrm{mol}$. Note that for dextran $40 \mathrm{~kg} / \mathrm{mol}, M_{\mathrm{n}}=21 \mathrm{~kg} / \mathrm{mol}$, and $M_{\mathrm{w}}=40$ $\mathrm{kg} / \mathrm{mol}$

The number average molecular weight of dextran was $20 \mathrm{~kg} /$ mol with a polydispersity of 1.9 . This indicates that the molecular weight of the dextran released from the microspheres was not significantly different from the molecular weight dextran used to prepare the dex-HEMA $\left(M_{\mathrm{n}}=21 \mathrm{~kg} / \mathrm{mol}, M_{\mathrm{w}}=40\right.$ $\mathrm{kg} / \mathrm{mol})$. The number average molecular weight of the methanolsoluble pHEMA degradation products in fraction B1 ranged between 26 and $82 \mathrm{~kg} / \mathrm{mol}$ with a polydispersity between 1.5 and 2.
The molecular weight of the insoluble pHEMA could not be determined, as it dissolved neither in methanol nor in other organic solvents (DMSO, DMF). The insoluble fraction showed significant swelling in DMSO. Because high molecular weight pHEMA is soluble in DMSO,${ }^{46}$ this result suggests that the insoluble residual material consists of a loosely cross-linked pHEMA. The mechanism behind the cross-linking pHEMA is not clear yet and requires further investigation.

\section{Conclusions}

This study demonstrates that the degradation of dex-HEMA microspheres in phosphate buffer $\mathrm{pH} 7.4,37{ }^{\circ} \mathrm{C}$ results in the formation of the water-soluble degradation products $(\sim 86-99 \%)$ and a small fraction of water-insoluble degradation products ( $4-14 \%)$. Under physiological conditions, water-soluble degradation products are gradually released as a result of the hydrolysis of cross-links and consist of dextran and small amounts of low molecular weight pHEMA $\left(M_{\mathrm{n}}\right.$ ranging between 14 and $16 \mathrm{~kg} / \mathrm{mol}$ ), unreacted HEMA, and HEMA-DMAP (intermediate reaction product of the Baylis-Hillman reaction of HEMA with DMAP). Water-insoluble degradation products consist of slightly cross-linked pHEMA and a small fraction of methanol-soluble, high molecular weight pHEMA $\left(M_{\mathrm{n}}\right.$ ranging between 27 and $82 \mathrm{~kg} / \mathrm{mol}$ ).

The dex-HEMA microspheres are promising biocompatible controlled delivery devices. For these systems, a low level of impurities and complete removal of the degradation products at the site of administration is preferred. Therefore, the in vivo degradation and the processing of the insoluble residue by macrophages ${ }^{47}$ and the mechanism of formation of cross-linked pHEMA are currently under investigation. Finally, the synthesis of dex-HEMA is optimized to avoid the formation of HEMADMAP.

Acknowledgment. We thank L. Vernooij and M. Leemhuis for valuable assistance and discussions.

\section{References and Notes}

(1) Sinha, V. R.; Trehan, A. J. Controlled Release 2003, 90, 261-280.

(2) Anderson, J. M.; Shive, M. S. Adv. Drug Delivery Rev. 1997, 28, 5-24.

(3) Anderson, J. M. Eur. J. Pharm. Biopharm. 1994, 4, 1-8.

(4) Cleland, J. L.; Mac, A.; Boyd, B.; Yang, J.; Duenas, E. T.; Yeung, D. Pharm. Res. 1997, 14, 420-425.

(5) Lu, W.; Park, T. G. J. Pharm. Sci. Technol. 1995, 49, 13-19.

(6) Van de Weert, M.; Hennink, W. E.; Jiskoot, W. Pharm. Res. 2000 17, 1159-1167.

(7) Schwendeman, S. P. Crit. Rev. Ther. Drug Carrier Syst. 2002, 19 73-98.

(8) Determan, A. S.; Trewyn, B. G.; Lin, V. S.; Nilsen-Hamilton, M.; Narasimhan, B. J. Controlled Release 2004, 100, 97-109.

(9) Van de Weert, M.; van Steenbergen, M. J.; Cleland, J. L.; Heller, J.; Hennink, W. E.; Crommelin, D. J. A. J. Pharm. Sci. 2002, 91, 10651074

(10) Heller, J.; Barr, J.; Ng, S. Y.; Abdellauoi, K. S.; Gurny, R. Adv Drug Delivery Rev. 2002, 16, 1015-1039. 
(11) Tamada, J.; Langer, R. J. Biomater. Sci., Polym. Ed. 1992, 3, 31553.

(12) Tabata, Y.; Gutta, S.; Langer, R. Pharm. Res. 1993, 10, 487-496.

(13) Chia, H.-H.; Yang, Y.-Y.; Chung, T.-S.; Ng S.; Heller, J. J. Controlled Release 2001, 75, 11-25.

(14) Park, H.; Park, K. Pharm. Res. 1996, 13, 1770-1776.

(15) Anderson, J. M.; Langone, J. J. J. Controlled Release 1999, 57, $107-$ 113.

(16) Langer, R.; Peppas, N. A. AIChE J. 2003, 49, 2990-3006.

(17) Peppas, N. A.; Bures, P.; Leobandung, W.; Ichikawa, H. Eur. J. Pharm. Biopharm. 2000, 50, 27.

(18) Franssen, O.; Hennink, W. E. Int. J. Pharm. 1998, 168, 1-7.

(19) Stenekes, R. J. H.; Franssen, O.; van Bommel, E. M. G.; Crommelin, D. J. A.; Hennink, W. E. Pharm. Res. 1998, 15, 557-561.

(20) Franssen, O.; Stenekes, R. J. H.; Hennink, W. E. J. Controlled Release 1999, 59, 219-228.

(21) Van Dijk-Wolthuis, W. N. E.; Franssen, O.; Talsma, H.; van Steenbergen, M. J.; Kettenes-van den Bosch, J. J.; Hennink, W. E. Macromolecules 1995, 28, 6317-6322.

(22) Franssen, O.; Vandervennet, L.; Roders, P.; Hennink, W. E. J. Controlled Release 1999, 60, 211-221.

(23) Van Dijk-Wolthuis, W. N. E.; van Steenbergen, M. J.; Underberg, W. J. M.; Hennink, W. E. J. Pharm. Sci. 1997, 86, 413-417.

(24) Van Dijk-Wolthuis, W. N. E.; Hoogeboom, J. A. M.; van Steenbergen, M. J.; Tsang, S. K. Y.; Hennink, W. E. Macromolecules 1997, 30, 4639-4645.

(25) Cadée, J. A.; Brouwer, L. A.; den Otter, W.; Hennink, W. E.; van Luyn, M. J. A. J. Biomed. Mater. Res. 2001, 56, 600-609.

(26) Meyvis, T. K. L.; De Smedt, S. C.; Demeester, J.; Hennink, W. E. Macromolecules 2000, 33, 4717-4725.

(27) Stubbe, B. G.; Braeckmans, K.; Horkay, F.; Hennink, W. E.; De Smedt, S. C.; Demeester, J. Macromolecules 2002, 35, 2501-2505.

(28) Stubbe, B. G.; Hennink, W. E.; De Smedt, S. C.; Demeester, J Macromolecules 2004, 37, 8739-8744.

(29) De Geest, B. G.; Déjugnat, C.; Sukhorukov, G. B.; Braeckmans, K.; De Smedt, S. C.; Demeester, J. Adv. Mater. 2005, 17, 2357-2361.
(30) Horák, D.; Jayakrishnan, A.; Arshady, R. In Introduction to Polymeric Biomaterials; Arshady, R., Ed.; Citus Books: London, 2003; Vol. 1 , pp 65-107.

(31) Weaver, J. M.; Bannister, I.; Robinson, K. L.; Bories-Azeau, X.; Armes, S. P. Macromolecules 2004, 37, 2395-2403.

(32) Van Dijk-Wolthuis, W. N. E.; Tsang, S. K. Y.; Kettenes-van den Bosch, J. J.; Hennink, W. E. Polymer 1997, 38, 6235-6242.

(33) Stenekes, R. J. H.; Hennink, W. E. Polymer 2000, 41, 5563-5569.

(34) Stenekes, R. J. H.; De Smedt, S. C.; Demeester, J.; Sun, G.; Zhang, Z.; Hennink, W. E. Biomacromolecules 2000, 1, 696-703.

(35) Zhang, Z.; Saunders, R.; Thomas, C. R. J. Microencapsulation 1999, $16,117-124$

(36) Sun, G.; Zhang, Z. J. Microencapsulation 2001, 18, 562-568.

(37) Thomas, C. R.; Zhang, Z.; Cowen, C. Biotechnol. Tech. 2001, 22, 593-602.

(38) Chung, J. T.; Vlugt-Wensink, K. D. F.; Hennink, W. E.; Zhang, Z. Int. J. Pharm. 2005, 288, 51-61.

(39) Baylis, A. B.; Hillman, M. E. D. German Patent 2155113, 1972; Chem. Abstr. 1972, 77, 34174.

(40) Basavaiah, D.; Rao, A. J.; Satyanarayana, T. Chem. Rev. 2003, 103, 811-891.

(41) Wolkers, W. F.; Oliver, A. E.; Tablin, F.; Crowe, J. H. Carbohydr. Res. 2004, 339, 1077-1085.

(42) Kacurakova, M.; Mathlouthi, M. Carbohydr. Res. 1996, 284, 145157.

(43) Ji, X.-L.; Jiang, S.-C.; Qiu, X.-P.; Dong, D.-W.; Yu, D.-H.; Jiang, B.-Z. J. Appl. Polym. Sci. 2003, 88, 3168-3175.

(44) Lim, H.; Lee, Y.; Han, S.; Cho, J.; Kim, K. J. J. Vac. Sci. Technol., A 2001, 19, 1490-1496.

(45) Massia, S. P.; Stark. J. Biomed. Mater. Res. 2003, 56, 390-399.

(46) Beers, K. L.; Boo, S.; Gaynor, S. G.; Matyjaszewski, K. Macromolecules 1999, 32, 5772-5776.

(47) Mabilleau, G.; Moreau, M. F.; Filmon, R.; Basle, M. F.; Chappard, D. Biomaterials 2004, 25, 5155-5162.

BM060385Z 